\title{
PANCREATITIS AGUDA EN EL EMBARAZO: A PROPÓSITO DE UN CASO CÚNICO
}

\author{
Drs. Pablo Sanhueza R. ${ }^{1}$, Nicole Yaksic B. ${ }^{2 a}$, Karina Chahuán I. ', Jaime Corvalán A. ${ }^{1}$ \\ ${ }^{1}$ Departamento de Obstetricia y Ginecología, Facultad de Medicina, Sede Oriente, Universidad de Chile, Hospital \\ Dr. Luis Tisné Brousse. ${ }^{2}$ CESFAM Ignacio Domeyko, Municipalidad de Santiago.
}

aMatrona.

\section{RESUMEN}

Se describe el caso clínico de un embarazo complicado con pancreatitis aguda, destacándose la importancia del diagnóstico correcto y las opciones terapéuticas en pacientes embarazadas.

Paciente primigesta de 35 semanas con sospecha clínica de pancreatitis aguda y confirmación mediante amilasemia de $2.236 \mathrm{U} / \mathrm{L}$ y lipasemia de $1.930 \mathrm{U} / \mathrm{L}$, es tratada en forma conservadora. Al cuarto día de hospitalización se realiza operación cesárea por sufrimiento fetal. Evoluciona en buenas condiciones y es dada de alta luego de 15 días de hospitalización.

La pancreatitis aguda durante el embarazo es una grave complicación, debiéndose realizar un adecuado diagnóstico diferencial con patologías graves del embarazo, y efectuando un adecuado tratamiento para asegurar el bienestar materno y fetal.

\section{PALABRAS CLAVE: Pancreatitis aguda, embarazo}

\section{SUMMARY}

A 35 weeks pregnant woman with clinical symptoms and signs of pancreatitis, which confirmed with increase of amylase and lipase serum values. A cesarean section had to be performed because fetal distress. Newborn weight was $2.450 \mathrm{~g}$, Apgar score 6-9 and had a favorable outcome. Patient was discharged after 15 days of hospitalization.

Acute Pancreatitis in pregnancy is a severe condition that requires a prompt diagnosis and treatment to secure maternal and fetal well being. A correct management of this infrequent association remains of critical importance.

\section{KEY WORDS: Acute pancreatitis, pregnancy}

\section{INTRODUCCIÓN}

La pancreatitis aguda (PA) es una rara condición durante el embarazo, ocurriendo en aproximadamente el 0,03 a $0,09 \%$ de las embarazadas (1-3). Las posibles causas de PA en el embarazo son las mismas que en las pacientes sin esta condición, destacando la enfermedad litiásica de la vía biliar como la causa más frecuente $(67 \%$ a $100 \%)$, asociándose también con hiperlipidemia, ingestión de drogas, asociaciones virales y hereditarias, y en un número importante de pacientes a causas idiopáticas (17\%) (1-8). Con respecto a la enfermedad litiásica, durante el embarazo la vesícula biliar es más grande, con menos movilidad, y su vaciamiento es más lento que con respecto a 
pacientes no embarazadas, lo que condiciona la precipitación de partículas sólidas en la bilis y la formación de cálculos biliares $(4,6,9,10)$.

El cuadro clínico está caracterizado por dolor abdominal epigástrico, náuseas y vómitos, y en algunos casos se asocia a un síndrome febril. El diagnóstico diferencial debe establecerse con colecistitis aguda, apendicitis aguda, infarto mesentérico, embarazo ectópico complicado, hiperemesis gravídica, preeclampsia e hígado graso agudo, entre otras patologías $(3,4,8)$. El diagnóstico se confirma con medición sérica de amilasa o lipasa, las que se encuentran elevadas $(4,3,11,12)$.

El tratamiento es similar que en las pacientes no embarazadas, y es fundamentalmente de soporte con colecistectomía electiva después del parto, teniendo como objetivos la prevención y tratamiento de las alteraciones hemodinámicas, supresión de la excreción pancreática, restricción de ingesta de alimentos, tratamiento del dolor, prevención de posibles infecciones y tratamiento de las complicaciones, además del estudio de la condición fetal mediante ecografías y monitorización fetal $(1,4,6)$. En las pacientes embarazadas, el tratamiento quirúrgico debe ser reservado para aquellas pacientes en que empeora su condición a pesar del manejo conservador, y puede ser realizado por medio de una colecistectomía la que puede ser segura durante el primer trimestre y después de éste si es necesario $(1,3,4,9,12)$. Más recientemente, el tratamiento quirúrgico por medio de una esfinterotomía endoscópica ha demostrado ser un procedimiento seguro y previene la pancreatitis biliar recurrente $(1,3,4)$. El rol de la colecistectomía laparoscópica permanece controversial debido a reportes disímiles en cuanto a resultados maternos y fetales $(1,13)$.

Con respecto al término del embarazo, este puede estar indicado en caso de que la paciente no responda al tratamiento conservador o en presencia de complicaciones derivadas de PA $(4,12)$. La vía del parto permanece controversial, sin embargo algunos autores han establecido que la PA durante el embarazo no afecta la indicación de la vía del parto, y en ausencia de contraindicación para parto vaginal, éste es recomendado $(6,12)$. Los riesgos fetales están dados principalmente por la prematuridad, la que ocurre en aproximadamente el $60 \%$ de los casos $(6,12)$.

\section{CASO CLÍNICO}

Paciente primigesta de 22 años, sin antecedentes mórbidos, cursando un embarazo de $35+4$ semanas según fecha de última menstruación (FUM) y acorde con ecografía precoz realizada a las 9 semanas. Posterior a una transgresión alimentaria, consulta en la Urgencia de la Maternidad del Hospital Santiago Oriente, por un cuadro de 12 horas de evolución de dolor abdominal epigástrico intenso y vómitos alimentarios a repetición, asociado a contracciones uterinas leves. Al examen físico presenta presión arterial 132/ $87 \mathrm{mmHg}$, pulso 119 por minuto, temperatura axilar $36,8^{\circ} \mathrm{C}$. El examen abdominal revela dolor intenso a la palpación en epigastrio, útero grávido, feto único en presentación cefálica, latidos cardiacos fetales (LCF) en 138 por minuto, presencia de dinámica uterina de baja intensidad y frecuencia. Al examen genital destaca cuello blando, borrado un $30 \%$ y permeable 2 centímetros. A nivel dorsal destaca puño percusión dudosamente positivo a nivel del punto costovertebral izquierdo.

Ingresa a la unidad de alto riesgo obstétrico con los diagnósticos de: primigesta, embarazo de 35+4 semanas, observación de pancreatitis aguda, amenaza de parto prematuro.

Los exámenes de laboratorio revelan: proteinuria cualitativa negativa; glóbulos blancos $12.800 / \mathrm{mm}^{3}$, hematocrito $37,9 \%$, recuento de plaquetas $423.000 / \mathrm{mm}^{3}$; tiempo de protrombina 11,5 segundos (95\%); BUN 10,7; calcemia 9,7 mg/dl; creatininemia $0,8 \mathrm{mg} / \mathrm{dl}$; bilirrubina directa $0,2 \mathrm{mg} /$ dl; bilirrubina total 0,3 mg/dl; GGT $21 \mathrm{UI} / \mathrm{L}$; GOT/ AST 84 UI/L; GPT/ALT 99 UI/L; proteína C reactiva (PCR) $167 \mathrm{mg} / \mathrm{L}$; LDH $410 \mathrm{U} / \mathrm{L}$; amilasemia 2.236 $\mathrm{UI} / \mathrm{L}$. Registro basal no estresante (RBNS): reactivo, con dinámica uterina de baja frecuencia y duración.

Se confirma PA y es ingresada a la unidad de cuidados intensivos. Se indica régimen cero, hidratación parenteral, sonda nasogástrica, ranitidina $50 \mathrm{mg} \mathrm{c} / 8$ horas e.v. y tratamiento antibiótico con ampicilina $1 \mathrm{~g} \mathrm{c} / 6$ horas e.v. por la eventualidad de un parto prematuro.

A las 12 horas de su ingreso se realiza una ecografía abdominal que demuestra líquido libre a nivel del espacio infraesplénico, vesícula biliar sin cálculos y vía biliar fina, el páncreas parcialmente visualizado y el resto de las estructuras abdominales visibles dentro de límites normales. Se complementan exámenes con BUN de 12, cratininemia $0,8 \mathrm{mg} / \mathrm{dl}$, control de amilasemia de $1.848 \mathrm{U} / \mathrm{L}$, lipasa sérica $1.930 \mathrm{UI} / \mathrm{L}$ y triglicéridos plasmáticos de $241 \mathrm{mg} / \mathrm{dl}$.

La paciente evoluciona favorablemente, con cese de la dinámica uterina, catalogándose como una PA leve según los criterios de Ranson y APA- 
CHE II. La ecografía obstétrica muestra una gestación única de $35+4$ semanas, feto en percentil 25 de la curva de crecimiento.

Luego de 24 horas los exámenes revelan un hematocrito 37\%; glóbulos blancos en $20.900 /$ mm3; glicemia $71 \mathrm{mg} / \mathrm{dl}$, albúmina plasmática de $1,5 \mathrm{~g} / \mathrm{dl}$ por lo que se inicia nutrición parenteral. Luego de 36 horas se controla amilasemia de 191 $\mathrm{UI} / \mathrm{L}$ y PCR de $314,2 \mathrm{mg} / \mathrm{L}$.

Al tercer día se realiza RBNS, que muestra una frecuencia cardíaca basal normal, con una variabilidad a largo plazo disminuida y una desaceleración espontánea hasta 90 latidos cardiofetales por minuto de 3 minutos de duración, que se recupera espontáneamente. Al cuarto día la ecografía evidencia oligoamnios severo, por lo que ante la ausencia de condiciones obstétricas favorables para parto vaginal, se decide realizar una operación cesárea. Se extrae un recién nacido masculino de $2.450 \mathrm{~g}$, Apgar 6-9. Durante el operatorio se toma muestra de líquido peritoneal para estudio de Gram y cultivo, y se inicia tratamiento antibiótico profiláctico con ciprofloxacino $200 \mathrm{mg}$ cada 12 horas e.v. y metronidazol $500 \mathrm{mg}$ cada 8 horas e.v. los que se mantienen por 10 días. En el resultado de la tinción de Gram se observan solo gran cantidad de polimorfonucleares, el cultivo es negativo luego de 48 horas de observación.

La paciente evoluciona favorablemente, con exámenes en regresión, con amilasemia al $4^{\circ}$ y $6^{\circ}$ día de hospitalización de 122 U/L y 120 U/L, respectivamente.

Al $7^{\circ}$ día la tomografía axial computarizada, revela líquido en espacio hepatorrenal derecho y peripancreático, páncreas severamente aumentado de tamaño en forma difusa especialmente con relación a la cola, presencia de áreas hipodensas en región corporal y cuello que corresponden a zonas de necrosis; los hallazgos son compatibles con una PA tipo $E$, según clasificación de Balthazar-Ranson. El mismo día se inicia nutrición enteral por medio de sonda nasoyeyunal, suspendiéndose al $9^{\circ}$ día la nutrición parenteral. Al $12^{\circ}$ día se inicia alimentación oral progresiva. Finalmente al $13^{\circ}$ día es trasladada a sala y es dada de alta en buenas condiciones al $15^{\circ}$ día de su ingreso.

\section{DISCUSIÓN}

La pancreatitis aguda durante el embarazo es una rara condición. En nuestro medio son escasos los reportes sobre esta asociación y por lo tanto desconocemos su frecuencia, aunque considerando la elevada prevalencia de enfermedad de la vía biliar en las mujeres chilenas, podríamos inferir que la incidencia de la pancreatitis aguda asociada al embarazo en nuestra población podría ser mayor que la reportada en estudios internacionales.

El diagnóstico es difícil de realizar debido principalmente a su baja frecuencia, debiéndose considerar como diagnósticos diferenciales, gastritis aguda, hiperemesis gravídica, hígado graso agudo del embarazo y preeclampsia severa. Es fundamental confirmar el diagnóstico con amilasa o lipasa sérica y realizar el estudio ultrasonográfico de la vía biliar, como también el estudio mediante tomografía axial computada con el fin de analizar la condición pancreática y establecer criterios pronósticos y de gravedad de la enfermedad. Como medida terapéutica, es necesario la hospitalización en una unidad de cuidados intensivos con el fin de brindar el mejor tratamiento conservador posible.

El manejo quirúrgico debe ser planteado en las pacientes en las que se ha comprobado el origen biliar y que presentan complicaciones a pesar del manejo conservador, o idealmente posterior al parto. La vía de abordaje quirúrgica debe ser decidida según la condición de la paciente, la edad gestacional y la experiencia del equipo quirúrgico. Se consideran medidas relativamente seguras la colecistectomía por laparotomía y la enfinterotomía endoscópica. Con respecto al manejo obstétrico, debe evaluarse la condición fetal mediante ecografía y monitorización electrónica de la frecuencia cardíaca fetal. La interrupción del embarazo se indica frente a complicación grave materna o alteración de la unidad feto placentaria.

\section{BIBLIOGRAFÍA}

1. Barthel JS, Chowdhury T, Miedema BW. Endoscopic sphincterotomy for the treatment of gallstone pancreatitis during pregnancy. Surg Endosc 1998; 12(5): 394-399.

2. Badja N, Troche G, Zazzo JF, Benhamou D. Acute pancretitis and preeclampsia-eclampsia: a case report. Am J Obstet Gynecol 1997; 176(3): 707-709.

3. Ramin KD, Ramin SM, Richey SD, Cunningham FG. Acute pancreatitis in pregnancy. Am J Obstet Gynecol 1995; 173(1): 187-191.

4. Scott LD. Gallstone disease and pancreatitis in pregnancy. Gastroenterol Clin North Am 1992; 21(4): 803-815.

5. Keilson LM, Vary CP, Sprecher DL, Renfrew R. Hyperlipidemia and pancreatitis during pregnancy in 
two sisters with a mutation in the lipoprotein lipase gene. Ann Intern Med 1996; 124(4): 425-8.

6. Beattie GJ, Keay S, Muir BB, Boddy K. Acute pancretitis with pseudocyst formation complicating pregnancy in a patient with a co-existent choledochal cyst. Br J Obstet Gynaecol 1993; 100(10): 957-9.

7. De Chalain TM, Michell WL, Berger GM. Hyperlipidemia, pregnancy and pancreatitis. Surg Gynecol Obstet 1988; 167(6): 469-73.

8. Hasselgren PO. Acute pancreatitis in pregnancy. Report of two cases. Acta Chir Scand 1980; 146(4): 297-9.

9. McKay AJ, O'Neill J, Imrie CW. Pancreatitis, preg- nancy and gallstone. $\mathrm{Br} \mathrm{J}$ Obstet Gynaecol 1980; 87(1): 7-50.

10. Block P, Kelly TR. Management of gallstone pancreatitis during pregnancy and the postpartum period. Surg Gynecol Obstet 1989; 168(5): 426-8.

11. Karsenti D, Bacq Y, Brechot JF, Mariotte N, Vol S, Tichet J. Serum amylase and lipase activities in normal pregnancy: a prospective case-control study. Am J Gastroenterol 2001; 96(3): 697-9.

12. Young KR. Acute pancreatitis in pregnancy: two cases reports. Obstet Gynecol 1982; 60(5): 653-657.

13. Lanzafame RJ. Laparoscopic cholecystectomy during pregnancy. Surgery 1995; 118: 627-33. 